\title{
Cultura e política em tempos de crise $^{1}$
}

Ugo Rivetti ${ }^{2}$

Culture and politics in a time of crisis

Cultura y política en tiempos de crisis

\section{Resumo}

Este artigo procura oferecer uma análise de alguns textos do crítico galês Raymond Williams dos anos 1960, à luz dos debates políticos que dominaram a cena da esquerda britânica da época. Com isso, pretendemos expor de que modo Williams procurou reagir a esses debates e se posicionar em meio a essas contendas, não só nos textos de intervenção mais direta e explícita como também em estudos críticos de maior fôlego. Trata-se, portanto, de ressaltar o lugar do político como elemento constitutivo de seu projeto teórico e, com isso, oferecer alguns elementos para uma compreensão um pouco mais bem acabada da trajetória de uma figura que sempre transitou entre o trabalho intelectual e a atuação política.

Palavras-chave: Raymond Williams; Partido Trabalhista; Reformismo; Nova esquerda.

\footnotetext{
1 Versão expandida de fala proferida no VI Colóquio de Pesquisa Educação e História Cultural, realizado na Faculdade de Educação da Universidade Estadual de Campinas, em março de 2019. Agradeço ao Prof. Alexandro Henrique Paixão, da FE-Unicamp, pelo convite para participar do evento e ao Prof. Daniel G. Williams, da Swansea University, por todo intercâmbio intelectual, decisivo para as reflexões que embasaram a redação deste texto.

2 Mestre em Sociologia pela Universidade de São Paulo e doutorando em Sociologia na mesma instituição (bolsistas Capes). E-mail: ugo.rivetti@usp.br.
} 
Abstract

This text proceeds to an analysis of some of Raymond Williams' works of the 1960s in relation to the political debates that dominated the scenario of the British left in those years. Therefore, we aim to show in which way Williams, even in his critical studies, sought to respond to those debates and to position himself amidst those disputes. Therefore, it highlights the political as an essential component of his theoretical project, and thus provide elements for a more polish comprehension of the life path of someone who has always circulated between intellectual work and political engagement.

Keywords: Raymond Williams; Labour party; Reformism; New left.

\section{Resumen}

Este texto procede a un análisis de algunas obras de Raymond Williams en los años 1960 respecto de los debates políticos que dominaran la escena de la izquierda británica desta época. Así, intentamos exponer en qué modo Williams, aún en sus estudios críticos, intentó reaccionar a esos debates y posicionarse en medio de estas disputas. Por lo tanto, se trata de resaltar el lugar de lo político como elemento constitutivo de su proyecto teórico, y con eso aportar a una comprensión más profundizada de la trayectoria de una persona que siempre transitó entre el trabajo intelectual y la actuación política.

Palabras clave: Raymond Williams; Partido Laborista; Reformismo; Nueva izquierda. 


\section{O Partido Trabalhista e as esquerdas}

"Qualquer análise do estado da esquerda na Grã-Bretanha deve começar com uma análise da natureza do Partido Trabalhista” (WILLIAMS, 1965a, p. 18). Ao menos no que se refere ao período da história britânica coberto por sua vida, a afirmação de Raymond Williams, impressa em artigo publicado originalmente na França em 1964, cuja tradução saiu na New Left Review no ano seguinte, diz (quase) tudo.

Tomando como referência a trajetória de Williams, a centralidade do Partido Trabalhista já se revela no espaço que essa instituição ocupou em seus anos de formação. Como destacado pelo próprio autor na longa entrevista concedida à New Left Review no final dos anos 1970 (WILLIAMS, 2013), a sua trajetória esteve entrelaçada desde o início ao movimento trabalhista britânico. Ele nasceu e cresceu em uma região da fronteira do País de Gales com a Inglaterra, que, embora distante dos grandes centros urbanos e estruturada economicamente em pequenas propriedades rurais familiares, contava com uma população trabalhadora sindicalizada bastante representativa e politizada (gravitando em torno da ferrovia que cortava a região), à qual pertencia seu pai - sinaleiro na estrada de ferro e ativo militante trabalhista. Além disso, a vida familiar em meio à qual se criou estava fortemente articulada à vida partidária, como se pode perceber quando ele recorda, ainda na entrevista à New Left Review, o impacto da vitória trabalhista nas eleições gerais de 1929: "[...] lembro-me da euforia em casa quando o Partido Trabalhista ganhou as eleições. Meu pai encabeçava o braço do partido em nosso vilarejo, e recebemos os resultados com festa” (WILLIAMS, 2013, p. 11); ou quando descreve como se vê, plenamente consciente das contradições em cena - o envolvimento de sua mãe com as questões políticas e partidárias: “Era a situação clássica da mulher no Partido Trabalhista. Ela faz o chá, endereça os envelopes e os entrega, mas não tem muita atividade política. Minha mãe, no entanto, tinha sua própria opinião” (WILLIAMS, 2013, p. 11). 
Além disso, de um ponto de vista mais geral, o Partido Trabalhista se manteve, ao longo de toda a vida de Williams, como o centro de gravidade da esquerda britânica, como a instituição que plasmou, direta e indiretamente, o cenário político e intelectual no qual tanto seus apoiadores como seus mais ferrenhos adversários na esquerda teriam de intervir. Essa circunstância remete ao dado mais fundamental da centralidade da tradição democrática e parlamentar na vida política e social britânica, o que explica não só a importância do trabalhismo, mas também a posição marginal a que o Partido Comunista da Grã-Bretanha foi relegado ao longo de todo o século XX³ . O peso dessa tradição democrática e parlamentar se fez presente na história do Partido Trabalhista desde o seu início, já quando foi fundado, em fevereiro de 1900, tendo como matriz principal a Sociedade Fabiana (fundada em 1884), corrente socialista que

\begin{abstract}
[...] se coloca resolutamente em uma perspectiva de socialismo reformista. Ela vai contra o messianismo revolucionário dos social-democratas ou dos anarquistas. Em lugar de anunciar a transformação próxima da ordem existente, ela se opõe a todo recurso à violência. Paciência e tempo permitirão realizar o socialismo respeitando inteiramente a liberdade de cada um. Dessa forma, os fabianos estão entre os pioneiros do socialismo democrático. (BÉDARIDA, 1974, p. 363, grifos no original)
\end{abstract}

Mas se o Partido Trabalhista se constituiu, desde o início, como a organização política por excelência da tradição socialista democrática e parlamentar, isso não significa que ele se alinhasse em bloco a essa vertente. Ao contrário, desde a sua fundação, o Partido Trabalhista se viu cindido em diferentes tendências, dispostas, grosso modo, segundo a oposição mais básica entre aqueles que defendiam uma ação política e partidária dirigida à transformação radi-

3 Quanto a isso, vale lembrar que, conforme destacou Paolo Spriano (1987), o comunismo britânico somente veio a desempenhar um papel político mais relevante justamente no contexto da frente antifascista estabelecida durante a Segunda Guerra Mundial, quando se aliou a correntes socialistas mais moderadas e alinhadas à tradição democrática. 
cal das estruturas da sociedade e da economia britânicas e os que - muitos deles vinculados aos sindicatos (os quais, por sua vez, exerciam grande influência na estrutura interna do partido) - reconheciam como objetivo maior a melhoria das condições de vida da população trabalhadora, ainda que ao preço da defesa de medidas que pareciam a seus adversários na esquerda excessivamente reformistas ${ }^{4}$.

Embora essa divisão estivesse presente desde o nascimento do partido, ela assumiu proporções novas, passando a repercutir por toda a esquerda britânica, a partir da segunda metade dos anos 1940, quando os trabalhistas retornaram ao poder com o gabinete liderado por Clement Attlee (1945-1951)5. Apesar de ter representado a concretização de um dos pontos nevrálgicos da política econômica defendida no estatuto do partido, a bem-sucedida política de nacionalização de importantes setores da economia (como transporte, eletricidade, gás e mineração) levada a cabo pelo governo trabalhista do pós-guerra conduziu os trabalhistas, paradoxalmente, a um impasse, como mostrou Bogdanor (1970). Ao concretizarem esse programa de nacionalização econômica, as fileiras trabalhistas não só se viram destituídas de sua principal bandeira política como também foram empurradas para uma posição defensiva, de oposição a governos conservadores que não procuraram reverter as políticas de nacionalização implantadas por seus adversários. Essas implicações das políticas que lançaram as bases do Estado de bem-estar social britânico também alimentavam entre as correntes trabalhistas a certeza da urgência de esforços de renovação, tanto nas linhas de ação política como na abordagem teórica que deveria subsidiá-las. Foi nesse quadro que as diferenças e o embate entre aquelas duas grandes abordagens se acentuaram.

\footnotetext{
4 "Por partos sucessivos o Partido Trabalhista conseguiu nascer, mas ele permaneceu a criança disputada do casamento ambíguo contraído entre o sindicalismo e o socialismo. Cada um dos pais tem o sentimento de incompatibilidade e, por consequência, se esforça para puxar a criança para o seu lado" (BÉDARIDA, 1974, p. 385).

5 É possível estimar o significado que a vitória trabalhista nas eleições de 1945 tem na história do partido, quando se atenta para o fato de que foi com ela que se constituiu pela primeira vez um governo de maioria trabalhista, diferentemente das experiências anteriores dos governos Ramsay MacDonald (1924; 1929-1935).
} 
Essas disputas internas resultaram em uma guinada ainda mais acentuada do partido em direção a posições reformistas. Esse movimento se traduziu em termos teóricos no protagonismo crescente de correntes revisionistas, para as quais o partido deveria se dedicar ao aprimoramento do capitalismo britânico por meio de reformas, notadamente "reformas fiscais e educacionais dentro do quadro da economia mista” (BOGDANOR, 1970, p. 89). Mas esse deslizamento para a direita também continha uma dimensão propriamente política, na medida em que novas lideranças afinadas às correntes revisionistas ascenderam a posições de comando, com destaque para aqueles que sucederam a Attlee na liderança do partido, Hugh Gaitskell (1955-1963) e Harold Wilson (1963-1976). Foram essas correntes intelectuais e lideranças políticas, ambas de matiz reformista, que conduziram o partido de volta ao poder, nas eleições gerais de outubro de 1964. Não por acaso, o governo trabalhista que se formou então, sob a liderança de Wilson (1964-1970), colocou em prática políticas que suscitariam a oposição de correntes mais à esquerda, como o alinhamento à política externa norte-americana, o desenvolvimento do programa nuclear britânico - combatido por aquele que foi um dos movimentos políticos mais importantes da Grã-Bretanha da época, a Campaign for Nuclear Disarmament - e o recurso a medidas inflacionárias e recessivas com vistas a combater o déficit da balança de pagamentos.

A nova esquerda de Williams, E. P. Thompson e Stuart Hall (para citar apenas os principais nomes dessa corrente) estava entre as forças da esquerda britânica que se opuseram à guinada reformista do Partido Trabalhista e às políticas do governo Wilson. Como enfatizado pelas inúmeras reconstruções da história do surgimento desse movimento (ANDERSON, 1965; CHUN, 1993; HALL, 1989; RUSTIN, 1989), a nova esquerda britânica nasceu encampando o projeto de oferecer uma alternativa política e teórica às duas correntes dominantes no movimento socialista da época: as tendências autoritárias e sectárias do movimento comunista, ainda em crise pela revelação dos crimes de Stalin em 1956; e os impulsos reformistas e revisionistas da social-democracia 
e de sua encarnação britânica, o Partido Trabalhista. Indício de como os debates no interior do partido reverberavam para além de suas fronteiras, a nova esquerda procurou se colocar não apenas como alternativa ao trabalhismo inglês, mas também às duas correntes nas quais ele se encontrava então dividido: tanto o revisionismo reformista e a sua adesão ao consenso político do pós-guerra, como a esquerda trabalhista com sua incapacidade (ou, para alguns, indisposição) para elaborar um diagnóstico adequado das novas configurações do capitalismo. Nas palavras de Stuart Hall (2014, p. 226):

A crítica ao reformismo e ao seu singular representante britânico, o trabalhismo, foi perpetrada pelo discurso alargado sobre "o político”. Nós buscávamos uma transformação mais radical e estrutural da sociedade: em parte porque estávamos comprometidos com muitas das perspectivas fundamentais do programa socialista clássico; em parte porque víamos, no capitalismo moderno, uma maior concentração do poder social e podíamos traçar o impacto da "mercantilização" em regiões mais afastadas das áreas de exploração do trabalho assalariado; mas, acima de tudo, por conta da crítica mais ampla “à civilização e à cultura capitalistas”. Ninguém expressou o caráter constitutivo e fundamental desse argumento feito pela e na New Left mais profundamente do que Raymond Williams.

Na condição de intelectual que, como tal, já gozava - desde a publicação de Cultura e sociedade, em 1958 - de uma estatura pública, Williams não se furtou a tomar posição em relação às questões que dominavam o universo da esquerda britânica da época: tanto nos debates suscitados pelo partido dominante nesse campo, como nas políticas empreendidas pelo governo por ele liderado. Como a passagem de Hall acima reproduzida deixa ver, é também essa tomada de posição de Williams o que explica, em certa medida, a influência por ele exercida sobre seus contemporâneos da nova esquerda. Mesmo o novo clima político e intelectual que tornou possível o aparecimento dessa nova corrente foi decisivo para que Williams se desvencilhasse da situação 
de isolamento na qual ele viveu ao longo dos anos 1950, cujas causas, como mostrou Dai Smith (2008), repousam não apenas em seu temperamento, mas sobretudo na hegemonia (política e cultural) do movimento comunista nos meios de esquerda, até o final daquela década.

Mas, ainda assim, resta a pergunta: seria possível rastrear o impacto dessas questões e desses debates em sua obra? Ou, para empregar termos mais próximos ao que poderia ser qualificado como uma abordagem "williamsiana" do problema: em que sentido os textos de Williams dos anos 1960 podem ser lidos (ou não) como reações à conjuntura política da época? Ou, ainda, em que medida a articulação entre a atividade intelectual e a conjuntura política se revela não apenas na trajetória do autor, mas também no desenvolvimento de seu argumento teórico?

\section{O consenso político do pós-guerra}

Assumindo como objeto de análise os textos de Williams dos anos 1960, já é possível identificar na conclusão a The Long Revolution (1961) um enfrentamento mais explícito dessas questões ${ }^{6}$. Adotando o procedimento (que se tornaria uma das marcas de sua abordagem) de pensar o problema em questão em um quadro mais amplo e inclusivo, Williams inscreve a conjuntura da Grã-Bretanha dos anos 1960 no contexto do processo mais geral por ele qualificado como uma "longa revolução".

Estivemos tentando desenvolver métodos de análise que, sobre um leque que vai da literatura às instituições so-

\footnotetext{
6 É possível identificar aqui uma especificidade não só de The Long Revolution, mas também de Cultura e sociedade, na medida em que, nesses dois casos, Williams se vale dos capítulos de conclusão para enfrentar de forma mais direta a situação conjuntural na qual estava escrevendo, o que explica, em alguma medida, o contraste de tom entre esses capítulos e aqueles que os antecedem. Com relação à conclusão de Cultura e sociedade, Smith (2008, p. 418) diz o seguinte: "A conclusão de Williams em Cultura e sociedade era a coisa mais impressionante sendo pensada e escrita na Grã-Bretanha no outono de 1956. [...] Assim como o próprio livro, essas quarenta e poucas páginas de meados dos anos 1950 foram rapidamente absorvidas à estrutura de sentimento dos anos 1960 como se fossem um lugar-comum. [...] Isso era cultura como política de um novo tipo e suas recortadas sentenças epigramáticas eram os alicerces de um manifesto”.
} 
ciais, possam articular estruturas de sentimento reais os significados e valores vividos em obras e relações - e clarificar os processos de desenvolvimento histórico pelos quais essas estruturas se formam e se modificam. Tentarei, nesta parte, uma descrição da Grã-Bretanha contemporânea nesse sentido [...] oferecendo uma descrição da linguagem essencial - os significados criados e criativos - que nossa realidade herdada ensina e pelos quais uma nova realidade se forma e é negociada. O contexto que dou a essa descrição particular é o processo histórico que denominei de longa revolução. (WILLIAMS, 1965b, p. 319)

Em outras palavras, Williams está muito mais interessado em enfatizar as linhas de continuidade entre o momento em que escreve (e que analisa) e o longo processo histórico, inaugurado no final do século XVIII, de transformações radicais na economia (com a industrialização), na política (com o avanço da democracia) e na cultura (com a expansão dos sistemas de educação e dos meios de comunicação). Para além do projeto de expor as bases de uma análise alternativa da cultura, Williams pretende avançar, em The Long Revolution, na compreensão da dimensão cultural desse amplo processo histórico - segundo ele, deixada de lado pela maior parte dos analistas -, examinando, entre outros tópicos, as mudanças no sistema educacional, na imprensa, no público leitor e nos padrões de recrutamento social dos escritores.

Esse enquadramento mais geral desempenhou um papel decisivo na elaboração do argumento de Williams. Pois, como vimos anteriormente, na base das correntes intelectuais e políticas que assumiram o comando do Partido Trabalhista nos anos 1950 estava não apenas uma concepção específica da ação política, mas também uma determinada concepção de história, cujo corolário principal era a defesa de uma ação política restrita aos limites da ordem capitalista. Opondo-se a essas correntes e à concepção do desenvolvimento histórico por elas encampada, Williams dirá que a longa revolução iniciada com o processo de industrialização, na virada do século XVIII para o XIX, não 
somente ainda não se completara no início dos anos 1960, como a sua continuidade dependeria dos conflitos políticos e sociais atravessando a sociedade.

O diagnóstico de época apresentado por Williams também se apoia nesse enquadramento mais geral. Assim, segundo ele, a trajetória recente do Partido Trabalhista integra um processo mais amplo de adesão do movimento trabalhista e de suas instituições aos "modos de pensamento aos quais eles ainda se opõem formalmente” (WILLIAMS, 1965b, p. 328). Ao longo desse processo, não só os movimentos operário e trabalhista deixam de se colocar como fontes de modos alternativos de desenvolvimento social, como também suas ações passam a ser redirecionadas no sentido do fortalecimento daqueles modos de pensamento e da organização da qual eles emanam, o capitalismo, definido aqui como "um sistema particular e temporário de organização do processo industrial” (WILLIAMS, 1965b, p. 327).

Em que medida as instituições da classe operária inglesa aderiram ao consenso do pós-guerra - segundo o qual a ação política tem como limite o aprimoramento das condições de vida no capitalismo - e até que ponto as suas iniciativas e ações passaram a ser dirigidas para o fortalecimento desse consenso e da organização social que ele traduz, isso fica claro, segundo Williams, quando se atenta para os limites a que estavam sujeitas as políticas de extensão dos serviços sociais e de nacionalização de setores-chave da economia e da indústria, empreendidas pelo governo trabalhista do pós-guerra. Limites que, como mostra Williams, decorriam do dado mais fundamental de que todas essas ações, apesar das transformações, foram postas em um quadro determinado pela estrutura capitalista:

A extensão dos serviços sociais, incluindo a educação, é um inquestionável ganho desse tipo, que não deve ser subestimado por aqueles que simplesmente herdaram-no. Mas continua sendo verdade que não apenas os serviços sociais têm sua operação limitada aos interstícios da sociedade de propriedade privada, mas 
também de que, em sua operação presente [actual], eles permanecem limitados pelos pressupostos e pelas regulações pertencentes não à nova sociedade, mas à antiga. (WILLIAMS, 1965b, p. 329-330)

É quando se enquadra o problema nesse plano mais geral que se pode criticar também a plataforma da "revolução científica" de Wilson: no fundo, argumenta Williams, que o fato de que gerentes e técnicos passem a exercer funções cada vez mais centrais, inclusive em substituição aos próprios proprietários, não produz nada de substancialmente novo, uma vez que a economia continua a ser controlada por "poderosas instituições privadas interligadas que de fato comandam o que alguns políticos trabalhistas ainda chamam melancolicamente 'os escalões dominantes [commanding Heights] da economia”" (WILLIAMS, 1965b, p. 331). Resumidamente, assim como as iniciativas do governo trabalhista de 1945, as medidas propostas e colocadas em prática pelo governo trabalhista eleito em 1964 não miravam as bases da estrutura econômica.

Também é nesse quadro que Williams procura compreender o recurso crescente das instituições do movimento operário britânico a ações defensivas e reativas: afinal, as políticas implantadas pelo governo trabalhista do pós-guerra e mantidas pelos governos conservadores que o sucederam - além das políticas de nacionalização da economia, toda a legislação social nas áreas de educação, seguro social e saúde (com a criação do National Health Service), por exemplo - produziram transformações que de fato resultaram em melhorias do padrão de vida. O detalhe decisivo, dirá Williams, é que esses avanços vieram acompanhados (e, em certa medida, foram viabilizados) por um fortalecimento do consenso político, de tal modo que não parecia possível à ação política ir além de posições defensivas. No novo contexto histórico produzido pelas políticas de bem-estar social, parecia que as únicas formas de oposição possíveis e eficazes seriam "o regateio e a amargura perpétuos da reivindicação salarial e da greve” (WILLIAMS, 1965b, p. 332). 


\section{Classes e ação política}

Intervindo de forma ainda mais clara no debate político da época, Williams também procurou oferecer uma explicação para as seguidas derrotas eleitorais do Partido Trabalhista, nos anos 1950, e para os deslocamentos ideológicos por ele descritos, ao longo daquela década. Para tanto, recusou a interpretação, em voga naquele momento, segundo a qual as derrotas dos trabalhistas decorreriam do progressivo desaparecimento de sua base social - a classe trabalhadora -, processo que resultaria, segundo essa interpretação, das mudanças econômicas em curso desde o fim da guerra e que teriam levado ao aparecimento de uma sociedade afluente ${ }^{7}$.

Essa tese deveria ser rejeitada, em primeiro lugar, porque, como vimos, para Williams as políticas colocadas em prática no pós-guerra produziram efeitos mais limitados do que aquela interpretação supunha; caso das medidas de nacionalização da economia, que mantiveram intocado o padrão de propriedade dos meios de produção, tido por Williams como o elemento determinante da estrutura econômica da sociedade capitalista. Em segundo lugar, aquela tese teria de ser descartada por se apoiar em uma concepção estreita de classe social, a partir da qual seria possível supor uma relação direta e necessária entre o pertencimento a uma classe e a preferência por determinado partido. Dando continuidade a um argumento desenvolvido anteriormente em Cultura e sociedade, Williams defenderá a necessidade de se conceber uma definição nova e alargada de classe. Assim, ele definirá as ideias e ações que podem ser associadas a uma classe específica como

a propriedade daquela parte de um grupo de pessoas, com circunstâncias semelhantes, que se tornou cons-

\footnotetext{
7 Contra essa interpretação, Williams argumenta que mesmo a elevação do padrão de vida de contingentes antes marginalizados não implica no desaparecimento da estratificação social em termos de classes: "Há muitos sinais de que o dinheiro, na forma da possessão conspícua de uma gama de objetos de prestígio, está rapidamente deslocando outras formas de distinção de classe, e é essa mudança que está por trás do argumento de que a distinção de classe está diminuindo. Isso é uma simples confusão de sentidos, pois é a realidade do tratamento diferencial, e não as formas particulares pelas quais ele opera, que faz um sistema de classe” (WILLIAMS, 1965a, p. 349).
} 
ciente de sua posição e de sua própria atitude com relação a essa posição. O sentimento de classe é um estilo, e não uma possessão uniforme de todos os indivíduos que poderiam, objetivamente, ser atribuídos àquela classe. [...] É absurdo interpretar indivíduos em termos rígidos de classe, porque a classe é um modo coletivo e não uma pessoa. Ao mesmo tempo, na interpretação das ideias e instituições, podemos falar propriamente em termos de classe. (WILLIAMS, 2011, p. 350)

Para Williams, portanto, as classes não se definem apenas em termos econômicos, mas também em termos de estilo de vida e comportamento, como uma experiência vivenciada diferentemente segundo critérios diversos, como gênero e localização geográfica. Ademais (e aqui residiria a causa principal da impropriedade de se supor uma relação necessária entre classe e voto), Williams argumenta que a consciência de classe não é um dado, mas uma construção tornada possível pela ação política e, portanto, o processo político de construção da consciência de classe deve figurar em primeiro plano em qualquer enfoque adequado das classes - assim como em qualquer política socialista, pois: "um proletariado pode ser factualmente criado por um sistema industrial, mas ele só será politicamente criado por ação política e, na Grã-Bretanha, isso nunca foi completamente alcançado” (WILLIAMS, 1965b, p. 357).

Ao propor uma definição alternativa àquela promovida pelas teorias da sociedade afluente, Williams estava interessado, também, em destacar a atualidade da classe como categoria analítica para a compreensão da sociedade inglesa de meados do século XX. Para ele, as teses que identificavam o desaparecimento das classes (reconhecendo nesse fenômeno um dos efeitos das políticas de bem-estar social) erravam no diagnóstico, porque perdiam de vista as mudanças históricas até ali transcorridas:

A verdadeira descrição é uma que reconheça que as definições tradicionais se quebraram e que a confusão resultante é uma diminuição séria da consciência. Novos tipos 
de trabalho, novas formas de capital, novos sistemas de propriedade requerem novas descrições do homem em suas relações com eles. (WILLIAMS, 1965b, p. 352)

A implicação política da tese alternativa proposta por Williams merece ser destacada: posto que a classe não é determinada apenas por condicionantes econômicos, e dados os limites das transformações pelas quais a sociedade britânica passara, então ainda restava a possibilidade da construção de um movimento socialista radical. Por outro lado, a tese de Williams assinala toda a impropriedade da conclusão dos partidários da tese da "desproletarização" (WILLIAMS, 1965, p. 353), segundo a qual o Partido Trabalhista deveria se conformar com o papel de oposição a sucessivos governos conservadores, caso insistisse em se manter como instituição do movimento trabalhista.

Embora seja possível identificar diversos tópicos nos quais Williams interveio mais diretamente no debate político da época, não se deve esquecer que as suas análises estavam apoiadas em um diagnóstico mais geral. E é nesse ponto que o peso das contendas políticas do início dos anos 1960 se faz sentir de forma mais substancial na construção de seu argumento teórico nessa época.

O cerne do diagnóstico de Williams é a tese segundo a qual a história recente do Partido Trabalhista integra o processo mais geral de adesão do movimento trabalhista e de suas instituições a um modo de pensamento que concebe a história em termos da "ideia de uma boa sociedade se desdobrando naturalmente” (WILLIAMS, 1965b, p. 319-20), como se os avanços obtidos fossem o produto de uma evolução natural e como se essas mudanças apontassem para "um país com um futuro bastante óbvio: industrialmente avançado, asseguradamente democrático e com um nível geral de educação e cultura continuamente ascendente” (WILLIAMS, 1965b, p. 319). Embora Williams não especifique aqui seus interlocutores, não há como não lembrar de Anthony Crosland (1918-1977), autor de The Future of Socialism (1956) e o mais destacado teórico revisionista, para quem o partido deveria assumir como nova meta a conquista de mais igualdade no interior do capitalismo, por meio de reformas 
pontuais; ou do programa da "revolução científica" de Harold Wilson em favor de um crescimento econômico mais robusto por meio de graduais avanços científicos e tecnológicos, sobretudo na indústria. Exporemos de forma mais detida, na seção seguinte, como Williams respondeu a essa tese e à concepção de história que estava na sua base.

\section{Crise e revolução}

Como destacou E. P. Thompson em uma resenha de The Long Revolution, publicada na New Left Review em 1961, há certa dissonância entre a conclusão do livro e os capítulos das duas partes que a antecedem, a qual se revela não apenas na natureza específica de um texto dedicado à análise de uma situação histórica mais conjuntural, mas também no próprio estilo da escrita de Williams. Aproveitando a sugestão da leitura de Thompson, vale ressaltar um aspecto específico do desnível por ele identificado e que diz respeito diretamente às questões examinadas neste texto.

Thompson centra a sua crítica naquilo que ele qualifica como as ênfases excessivamente gerais, abstratas e impessoais presentes no livro e que, segundo ele, aparecem mais claramente na definição que Williams oferece do processo da "longa revolução". Assim, embora toda revolução se coloque "contra algo (classes, instituições, pessoas, ideias) assim como em nome de algo” (THOMPSON, 1961a, p. 25), a longa revolução de Williams surge como um processo que se realiza na forma de amplas mudanças estruturais, as quais conduzem ao crescimento e desenvolvimento da organização social, por meio do avanço da industrialização, do aprofundamento da democracia e da expansão da cultura; como um processo que se mantém alheio aos atores sociais e aos conflitos que os opõem. Em resumo,

[...] não há homens bons ou maus na história do Sr. Williams, apenas "estruturas de sentimento" dominantes e subordinadas. No final, ficamos com uma euforia 
geral de "progresso"; o que quer que tenha acontecido, a ênfase recai sobre "crescimento", "expansão", "novos padrões”. (THOMPSON, 1961a, p. 29) ${ }^{8}$

Já na conclusão, o estilo de Williams se altera, assumindo um tom "mais autêntico e mais engajado” (THOMPSON, 1961b, p. 38), o que, segundo essa leitura, decorre do fato de o autor se apoiar nesse momento "menos em seu próprio sistema do que em uma compreensão da dialética do processo social - da lógica da mudança” (THOMPSON, 1961b, p. 38).

Segundo nos parece, é nesse novo registro que Williams trata da longa revolução na conclusão de The Long Revolution. Mais precisamente, é justamente no momento em que se bate mais diretamente com as teses do revisionismo trabalhista que Williams assinala um aspecto desse processo histórico, que permaneceu marginalizado até aquele momento de sua argumentação, o qual, como ele mostra, foi completamente desconsiderado pelas correntes reformista e ortodoxa do movimento socialista. Isto é, como já antecipado, em que medida a longa revolução, que tivera início na virada do século XVIII para o XIX, não só não tinha se completado no início dos anos 1960, como a sua continuidade dependeria de esforços concretos para aprofundar e estender os meios e instrumentos de participação democrática, como, por exemplo: na economia, com a gestão compartilhada das fábricas entre proprietários e trabalhadores; na cultura, com a atribuição aos produtores culturais da direção de suas próprias instituições; e na política, com a promoção de reformas nos sistemas eleitoral e partidário.

Que a elaboração da ideia de “longa revolução” seja um feixe, no qual a teoria de Williams se entrelaça com suas intervenções no debate político da época,

\footnotetext{
8 Vale citar uma passagem de Williams, à guisa de ilustração: "Me parece que estamos vivendo em meio a uma longa revolução, que nossas melhores descrições interpretam apenas em parte. Trata-se de uma revolução genuína, transformando homens e instituições; continuamente estendida e aprofundada pelas ações de milhões, continua e amplamente combatida por reação explícita e pela pressão de formas e ideias habituais. Ainda assim, ela é uma revolução difícil de ser definida, e a sua ação desigual se dá em um período tão longo que é praticamente impossível não se perder em seu processo excepcionalmente complicado" (WILLIAMS, 1965a, p. 10).
} 
fica evidenciado quando se atenta para outro texto bastante importante dos anos 1960. É bastante conhecida a afirmação de Williams, na introdução a The Long Revolution, de que esse livro, ao lado de Cultura e sociedade e de seu primeiro romance, Border Country, publicado em 1960, concluiria "um corpo de trabalho que me impus a fazer há dez anos” (WILLIAMS, 1965a, p. 15). Algo que não é lembrado com a mesma frequência é a afirmação que consta na introdução da Tragédia moderna (1966), segundo a qual a primeira parte desse livro "segue, em certos aspectos, a intenção que moveu a escrita de Cultura e sociedade e The Long Revolution" (WILLIAMS, 2002, p. 25). Para além das diferentes dimensões dessa linha de continuidade, vale destacar que esse outro texto pode ser lido como mais um passo no esforço de Williams por elaborar seu conceito de "longa revolução".

Aqui, Williams dirá que é necessário restituir à revolução a sua dimensão trágica - vale esclarecer, não como evento mergulhado no caos e na violência, mas como "uma ação total dos homens que vivem no presente" (WILLIAMS, 2002, p. 93) - e, nesse sentido, como um processo duplamente trágico, tanto em suas origens, porque "nasce em meio ao terror e à piedade: na percepção de uma desordem radical na qual a humanidade de alguns homens é negada” (WILLIAMS, 2002, p. 107), quanto em sua ação mesma, "no sentido de que não é contra deuses ou coisas inanimadas que o seu ímpeto combate, nem contra meras instituições ou estruturas sociais, mas contra outros homens” (WILLIAMS, 2002, p. 107).

Segundo Williams, essa rearticulação entre revolução e tragédia representa, entre outras coisas, uma reação às duas concepções de sociedade e história dominantes na Grã-Bretanha dos anos 1960, assim como às concepções de ação política que viriam a reboque de cada uma delas: de um lado, a perspectiva naturalista que, apoiada na "evolução como um modelo social" (WILLIAMS, 2002, p. 98), toma a história como um processo mecânico, que se desdobra por si mesmo e cujo destino estaria fora do alcance dos homens; 
de outro, a concepção romântica que restringe qualquer mudança possível ao plano individual. Desse modo, definir a revolução como um acontecimento trágico implica também em repensar a natureza do processo histórico e o estatuto da ação política.

À primeira vista, parece haver aqui um desvio no interior do projeto teórico que vinha sendo desenvolvido por Williams, uma vez que, se a reconstrução da história pelo prisma da longa revolução, sugeriria um processo destituído de luta e conflito (e esse é o cerne da crítica de Thompson), a acepção trágica de revolução agora proposta não apenas supõe, mas recupera a luta em seu aspecto mais concreto e violento. Essa leitura não dá conta, no entanto, de todos os sentidos e implicações contidos no argumento de Williams - e, aqui, a opção por apreciar o texto em contraste com os debates políticos da época justifica a sua consequência. Pois quando se atenta para o cenário da esquerda britânica da época, compreende-se por que Williams dedicou muito mais espaço e energia, em Tragédia moderna, ao enfrentamento da perspectiva que reduz a revolução ao caos e ao sofrimento e, portanto, vê na revolução algo que deve ser evitado a todo custo. A marginalidade da visão épica, laudatória da revolução tornava qualquer crítica mais cerrada dessa abordagem virtualmente desnecessária.

Para empregar os termos do recorte histórico mais abrangente adotado por Williams, poderíamos dizer que a grande força política da esquerda na Grã-Bretanha se encontrava, portanto, dominada por aquela visão "naturalista”, que vê a história como um processo mecânico, acima do poder de intervenção dos homens. Desse ponto de vista, o tom mais político e assertivo de Williams em Tragédia moderna pode também ser visto como reação a uma conjuntura na qual a nova esquerda e a esquerda trabalhista se achavam ainda mais distantes.

Recusando os pressupostos da perspectiva naturalista e, por extensão, do reformismo trabalhista, Williams dirá que a revolução não é a crise que deve 
ser evitada a todo custo, mas o esforço para a resolução da crise; não é o mergulho do mundo em caos e sofrimento, mas a luta pela superação da situação de caos e sofrimento na qual a revolução teve origem. Em suas palavras:

A ação trágica não é, no sentido mais profundo, a confirmação da desordem, mas a compreensão, a experiência e a resolução dessa desordem. Em nossa própria época, esta ação é geral e o seu nome usual é revolução. Temos de ver o mal e o sofrimento na desordem efetiva, que torna necessária a revolução, e na luta desordenada contra essa desordem. (WILLIAMS, 2002, p. 114)

Portanto, assim como reconhecer o caráter trágico da revolução não significa reduzi-la à violência, ao caos e à desordem, compreendê-la como o momento de agudização da crise, na qual ela própria teve origem, não significa tomá-la como evento isolado. Pelo contrário, Williams argumenta que a revolução só se realizará enquanto tal se implicar em uma transformação, de fato, radical e profunda.

Nesse ponto, Williams não apenas completa a rearticulação entre revolução e tragédia, mas também refina o seu conceito de "longa revolução": a revolução como tragédia constitui um momento da longa revolução - assim como, recorda ele, a revolução política constituía, em Marx, apenas um momento da “revolução humana geral” (WILLIAMS, 2002, p. 105). Assumindo-se esse ponto de vista, vê-se que a intenção de Williams em seu estudo sobre as ideias de tragédia não foi tanto revisar, mas desenvolver e, sobretudo, esclarecer o conceito de longa revolução e a concepção de história a ele subjacente, apresentados em The Long Revolution; esforço de esclarecimento que incluía: responder às críticas que esse livro havia suscitado (sobretudo nos meios de esquerda), posicionar-se no debate político da época e, para usar os termos empregados por Thompson em sua resenha, explicitar mais claramente as suas "não declaradas alianças ou premissas tradicionais” (THOMPSON, 1961b, p. 34). 


\section{Conclusão}

Com a análise desenvolvida, não tivemos a intenção de sugerir qualquer relação de causalidade entre obra e contexto político. A própria enunciação desses termos foi pensada simplesmente como ferramenta para tornar mais clara a exposição, não pretendendo, portanto, oferecer uma descrição literal dos polos de uma relação. Acima de tudo, tratava-se de oferecer alguns elementos para abordar a obra de Williams de um ponto de vista específico e, com isso, contribuir para a compreensão do enigma, comum a todos os expoentes da nova esquerda, da trajetória de alguém que, a todo momento, transitou entre estudos teóricos, críticos e textos de intervenção; entre os corredores das universidades e as reuniões políticas; entre jornais de grande circulação, revistas acadêmicas e manifestos. Julgamos que, assim como qualquer análise da esquerda britânica deve começar por uma análise do Partido Trabalhista, qualquer análise da obra e da trajetória de Williams deve passar por um enfrentamento desse enigma.

\section{Referências}

ANDERSON, Perry. The Left in the Fifties. New Left Review I/29, p. 3-18, jan./ feb. 1965.

BÉDARIDA, François. Le Socialisme en Grand-Bretagne de 1875 à 1914. In: DROZ, Jacques (Org.). Histoire Générale du Socialisme. 2 - De 1875 à 1918. Paris: Presse Universitaires de France, 1974, p. 347-399.

BOGDANOR, Vernon. The Labour Party in Opposition, 1951-1964. In: BOGDANOR, Vernon; SKIDELSKY, Robert. The Age of Affluence 1951-1964. London and Basingstoke: Macmillan, 1970, p. 78-116.

CHUN, Lin. The British New Left. Edinburgh: Edinburgh University Press, 1993.

CROSLAND, Anthony. The Future of Socialism. London: J. Cape, 1956. 
HALL, Stuart. Politics and Letters. In: EAGLETON, Terry (Ed.). Raymond Williams. Critical perspectives. Cambridge, Oxford: Polity Press, Basil Blackwell, 1989.

HALL, Stuart. Vida e época da primeira New Left. Plural, São Paulo, v. 21, n. 2, p. 214-234, dez. 2014.

RUSTIN, Michael. The New Left as a Social Movement. In: ARCHER, Robin. Out of Apathy: Voices of the New Left Thirty Years On: papers based on a conference organized by the Oxford University Socialist Discussion Group. London: Verso, 1989, p. 119-128.

SMITH, Dai. Raymond Williams: A Warrior's Tale. Cardigan: Parthian, 2008.

SPRIANO, Paolo. O movimento comunista entre a guerra e o pós-guerra. In: HOBSBAWM, Eric J. História do marxismo. O marxismo na época da Terceira Internacional: de Gramsci à crise do stalinismo. Rio de Janeiro: Paz e Terra, 1987. p. 129-212.

THOMPSON, E. P. The Long Revolution (Part I). New Left Review, London, v. I, n. 10, p. 24-33, may/jun. 1961a.

THOMPSON, E. P. The Long Revolution (Part II). New Left Review, London, v. I, n. 10, p. 34-39, jul./aug. 1961b.

WILLIAMS, Raymond. A política e as letras: entrevistas da New Left Review. São Paulo: Editora Unesp, 2013.

WILLIAMS, Raymond. Cultura e sociedade: de Coleridge a Orwell. Petrópolis: Vozes, 2011.

WILLIAMS, Raymond. The British Left. New Left Review, London, v. I, n. 30, p. 18-26, mar./apr. 1965a.

WILLIAMS, Raymond. The Long Revolution. Harmondsworth: Penguin Books, 1965b.

WILLIAMS, Raymond. Tragédia moderna. São Paulo: Cosac Naify, 2002. 